\title{
Certification in cardiothoracic surgical critical care
}

\author{
Hisham M. F. Sherif, MD, ${ }^{a}$ and Lawrence H. Cohn, MD $^{\mathrm{b}}$
}

In the June 2013 issue of the Journal of Thoracic and Cardiovascular Surgery, Dr Nevin Katz ${ }^{1}$ presents a strong argument in support of certification in the subspecialty of cardiothoracic surgical critical care (CTSCC) by the American Board of Thoracic Surgery (ABTS), instead of the current situation where such training, examination, and certification are delegated to the American Board of Surgery, as detailed by the response from the ABTS in the same issue.

More than 800 years ago, surgery as a scientific discipline did not exist. The first organization to provide any kind of standards for this practice originally started as a Fellowship of Barbers leading to the Worshipful Company of BarberSurgeons, because these were the ones assigned what were considered to be menial tasks, such as amputations and treatment of battlefield injuries. Because the training and practice were in the form of an apprenticeship to an artisan rather than according to rigorous academic education, such practitioners were deemed unworthy of the title of Doctor, a tradition still in existence in some countries today. ${ }^{2,3}$

The adoption of scientific method in the education, training, examination, certification, and credentialing of surgeons had to wait until the Royal Charter of 1800, establishing the Royal College of Surgeons in England; committed to "promoting and advancing the highest standards of surgical care for patients, and regulating the practice of surgery." 4 As the practice of surgery evolved and matured, and several specialties were more clearly defined, the corresponding organizations (ie, specialty Boards) emerged to establish the regulations and guidelines for education, training, and certification of candidates in those specific areas of practice.

This same scientific approach has been adopted by the ABTS, dedicated to "promoting effective, safe and ethical thoracic surgical practice by maintaining high standards for education, training and knowledge through examination, certification and maintenance of certification." Further to the point, the ABTS defines the practice of thoracic surgery as "the operative, perioperative, and surgical critical

\footnotetext{
From the Cardiac Surgery, ${ }^{\text {a }}$ Christiana Hospital, Newark, Del; and The Journal of Thoracic and Cardiovascular Surgery, ${ }^{\mathrm{b}}$ American Association for Thoracic Surgery, Beverly, Mass.

Disclosures: Authors have nothing to disclose with regard to commercial support.

Received for publication Nov 5, 2013; revisions received Dec 13, 2013; accepted for publication Jan 16, 2014; available ahead of print Feb 14, 2014.

Address for reprints: Hisham M. F. Sherif, MD, Cardiac Surgery, Christiana Hospital, 4755 Ogletown-Stanton Rd, Suite 1E50, Newark, DE 19718 (E-mail: hsherif@ christianacare.org).

J Thorac Cardiovasc Surg 2014;147:1454-5

$0022-5223 / \$ 36.00$

Copyright (c) 2014 by The American Association for Thoracic Surgery

http://dx.doi.org/10.1016/j.jtcvs.2014.01.023
}

care of patients with acquired and congenital pathologic conditions within the chest." 5

Based on these definitions, the ABTS provides rigorous, scientific, evidence-based criteria for didactic education through its approved curriculum for thoracic surgery, as well as strict requirements for clinical training in the form of residency and fellowships. Certification as proof of competency of the candidate to practice in this specialty is determined by written and oral examinations administered by the Board.

In April 2005, training and experience in congenital heart surgery was formally recognized by the ABTS as a subspecialty of thoracic surgery, leading to the establishment of an advisory committee to develop certification in congenital heart surgery, now attainable through 2 different pathways.

In 2008, the ABTS recognized that "cardiothoracic critical care has a set of skills and a knowledge base that are not covered by the critical care certificates that currently exist in other specialties." Subsequently, a motion was approved by the Board "to increase the importance of critical care within cardiothoracic surgery," 6,7 which provided the basis for adopting a resolution "to establish a separate certificate in cardiothoracic critical care." 8

Both instances demonstrate that the ABTS, as an independent governing organization since 1971, is the sole authority regarding the education, training, and certification in any specific area of practice it recognizes within the scope of thoracic and cardiovascular surgery.

However, the available pathways for training and certification in CTSCC are still provided exclusively through the American Board of Surgery. ${ }^{9}$ This has prompted the ABTS to post the following statement ${ }^{10}$ on its Web site:

The American Board of Thoracic Surgery considers it inappropriate to exclude its Diplomates from credentialing for care of thoracic surgical patients in a critical care setting based on the Diplomate's training or board certification. Our Diplomates have been trained in critical care management of thoracic surgical patients and they have successfully completed both written and oral examinations, which cover the critical care aspects of the thoracic surgical patients.

Without a doubt, it is highly commendable that the ABTS publicly registers its disapproval of the status quo regarding this matter. The cardiothoracic surgical community, especially those actively involved in CTSCC on a daily basis and/or as a career choice, welcomes this news and looks forward to more robust measures to follow from the ABTS to clearly define practical pathways for education, training, examination, and credentialing in CTSCC. 
This is especially important to attract more surgeons to this subspecialty, thereby creating a critical mass that will help to define the diverse areas of practice for the modern cardiothoracic surgeon and counteract the growing trend (primarily driven by financial and administrative considerations) to replace cardiothoracic surgeons in critical care units with nonsurgeon clinicians.

As Dr Katz elegantly affirms, it is indeed the right time for the governing organizations of the specialty; particularly the ABTS, to claim what is rightfully theirs. After all, the ABTS has been an independent body for decades, and its mission remains to implement sound scientific principles in the regulation and thus advancement of cardiothoracic surgical practice.

\section{References}

1. Katz NM. It is time for certification in cardiothoracic critical care. J Thorac Cardiovasc Surg. 2013;145:1446-7.

2. Pelling M. Barbers and barber-surgeons: an occupational group in an English provincial town, 1550-1640. Soc Soc Hist Med Bull (Lond). 1981;28: 14-6.

3. Gross D. Arnold Schlegel (1850-1924) and the Agony of the Barber-Surgeons as a Profession. Gesnerus. 1996;53:67-86.
4. The Royal College of Surgeons in England. Mission Statement. Available at: http://www.rcseng.ac.uk/about. Accessed November 4, 2013.

5. American Board of Thoracic Surgery. Mission Statement. Available at: https:// www.abts.org/root/home/mission-statement.aspx Accessed November 4, 2013.

6. Baumgartner WA. ABTS, past and present. Presented at: American Board of Thoracic Surgery Spring Meeting; October 2013.

7. American Board of Thoracic Surgery. Booklet of Information. Congenital Heart Surgery Subspecialty Certification. 2013:5. Available at: https://www.abts.org/ media/6497/congenital_heart_surgery_booklet_of_information.pdf. Accessed November 4, 2013.

8. ABTS adopts two new resolutions. Thoracic Surgery News. November/ December 2008. Available at: http://www.thoracicsurgerynews.com/fileadmin/ content_images/aats/issue_pdfs/2008_Issues/Thoracic-Surgery-News-Nov-Dec \%202008.pdf. Accessed November 4, 2013

9. Baumgartner W, Calhoon J, Shemin R, Allen M. Critical care: American Board of Thoracic Surgery update. J Thorac Cardiovasc Surg. 2013;145:1448-9.

10. American Board of Thoracic Surgery. Announcement. Cardiothoracic Critical Care. Available at: https://www.abts.org/root/home/critical-care.aspx. Accessed November 4, 2013.

11. Sherif HMF. Developing a curriculum for cardiothoracic surgical critical care: impetus and goals. J Thorac Cardiovasc Surg. 2012;143:804-8.

12. Skinner H, Skoyles J, Redfearn S, Jutley R, Mitchell I, Richens D. Advanced care nurse practitioners can safely provide sole resident cover for level three patients: impact on outcomes, cost and work patterns in a cardiac surgery programme. Eur J Cardiothorac Surg. 2013;43:19-22.

13. Markewitz A. Editorial comment: Nurse practitioners replacing young doctors: it works, but does it make sense? Eur J Cardiothorac Surg. 2013;43:23-4. 